\title{
Pfaffia Cipoana e Pfaffia rupestris (Amaranthaceae), DUAS NOVAS ESPÉCIES PARA O BRASIL
}

\author{
Maria Salete Marchioretto ${ }^{1}$, Silvia Teresinha Sfoggia Miotto ${ }^{2}$ \\ \& Josafá Carlos de Siqueira ${ }^{3}$
}

\section{Resumo}

(Pfaffia cipoana e Pfaffia rupestris (Amaranthaceae), duas novas espécies para o Brasil) Pfaffia cipoana e Pfaffia rupestris (Amaranthaceae) constituem-se novas espécies para a flora brasileira, inseridas na secção Pfaffia, a qual inclui o maior número de espécies no Brasil. Pfaffia cipoana é próxima de $P$. denudata diferenciando-se desta, principalmente, por apresentar folhas de comprimento e largura maiores e sépalas oblongas. Pfaffia rupestris diferencia-se por ser extremamente foliosa, com folhas diminutas, opostas e verticiladas. As referidas espécies foram reconhecidas no decorrer da revisão taxonômica do gênero Pfaffia para o Brasil. São apresentadas descrições, ilustrações, observações sobre o hábitat e a distribuição geográfica. Palavras-chave: taxonomia, novos táxons, campo rupestre, flora.

\begin{abstract}
(Pfaffia cipoana and Pfaffia rupestris (Amaranthaceae) two new species in Brazil) Pfaffia cipoana and Pfaffia rupestris (Amaranthaceae) are two new species of the Brazilian flora. These species are included in the section Pfaffia, which has the largest number of species in the Brazilian territory. Pfaffia cipoana is close to P. denudata but it is set apart mainly by the greater length and width of the leaves and oblong sepals. Pfaffia rupestris differs as it is extremely leafy, with small, opposite and verticillate leaves. The two species were recognized during the revision of the genus Pfaffia in Brazil. Descriptions, illustrations, observations about the habitat and the geographical distribution of the new species are presented.
\end{abstract}

Key words: taxonomy, new taxa, campo rupestre, flora.

\section{INTRODUÇÃO}

O gênero Pfaffia, embora muito próximo morfologicamente do gênero Gomphrena, difere do mesmo pelo tubo estaminal curto, filetes unidos até o meio e ciliados lateralmente, estilete quase sempre ausente e estigma bilobado ou capitado (Siqueira 1992). As espécies do gênero Pfaffia estão distribuídas na região neotropical, estendendo-se do sul do México através dos trópicos, incluindo a bacia Amazônica, até Baía Blanca na Argentina (Borsch 1995), sendo a Região Sudeste do Brasil o centro de diversidade do gênero (Siqueira 1994/1995).
Stützer (1935) realizou uma revisão do gênero para a América do Sul. Posteriormente poucos trabalhos foram realizados no Brasil abrangendo estados como Minas Gerais (Siqueira \& Grandi 1986), Rio Grande do Sul (Vasconcellos 1986) e São Paulo (Siqueira 2002). Para o Brasil são citadas 20 espécies com distribuição ampla ou restrita, principalmente em formações vegetacionais como cerrados, campos rupestres, campos limpos, orla de matas, beira de rios e capoeiras. Durante a revisão do gênero $P$ faffia, reconheceu-se duas novas espécies: Pfaffia cipoana e Pfaffia rupestris, aqui apresentadas.

Artigo recebido em 06/2007. Aceito para publicação em 12/2007.

${ }^{1}$ Pesquisadora e curadora do Herbarium Anchieta, Instituto Anchietano de Pesquisas, Rua Brasil 725, C.P. 275, 93001-970, São Leopoldo, RS. Doutoranda do Pós-graduação em Botânica da Universidade Federal do Rio Grande do Sul. herbariopaca@unisinos.br

2Professora do Departamento de Botânica, Universidade Federal do Rio Grande do Sul, Av. Bento Gonçalves, 9500, Bloco IV, prédio 43433, 91501-970, Porto Alegre, RS. Bolsista de Produtividade do CNPq

3Professor e Pesquisador do Departamento de Geografia e Meio Ambiente da PUC-Rio, Rua Marquês de São Vicente 398, 22451-041, Rio de Janeiro, RJ. 
1. Pfaffia cipoana Marchioretto, Miotto \& Siqueira $s p$. nov. Tipo: BRASIL. MINAS GERAIS: Itambé do Mato Dentro, Serra do Cipó (Sa. das Bandeirinhas), about $18 \mathrm{~km}$ by foot trail WNW of settlement of Serra das Alves, N. Sra do Carmo, 11.V.1982, N. Hensold 820 (holótipo PACA; isótipos SPF, NY).

Fig. 1

Pfaffia cipoana est Pfaffia denudata (Moq.) Kuntze affinis, a qua differt ramis foliosis, foliis laceolatis ad linearlanceolatis usque $3 \mathrm{~cm}$ longis, $0,2 \mathrm{~cm}$ largis differt; bractea medialis, margine hyalinus, nervo dorsali lato, castaneus, sepalis oblongis.

Subarbusto, caule ereto, ramos delgados, escuros, brilhantes, estriados, brevemente pilosos, tricomas setosos a híspidos, entrenós de 2,5-4,5 cm compr. Folhas opostas, lanceoladas a linearlanceoladas, $1,5-3 \times 0,1-0,2 \mathrm{~cm}$, sésseis, ápice agudo, base aguda ou decurrente, faces adaxial e abaxial glabras a brevemente pilosas, tricomas híspidos. Inflorescência capituliforme, terminal, pedúnculo curto a médio, 2,5-5 cm compr., estriado, piloso, tricomas híspidos, ferrugíneos, ráquis tomentosa; brácteas 3, a mediana ovada, bordos hialinos, nervura dorsal larga, escura, ápice apiculado a acuminado $1,5-1,8 \mathrm{~mm}$ compr., brácteas laterais ovadas a côncavas, quase hialinas, nervura dorsal proeminente, ápice acuminado, 1,5 mm compr., tricomas no dorso em direção ao ápice. Sépalas desiguais, três externas, oblongas, densamente pilosas no dorso, ápice agudo, ca. $4 \mathrm{~mm}$ compr., as internas um pouco menores, oblongas, densamente pilosas no dorso, ápice agudo. Tubo estaminal menor que as sépalas, filamentos laterais fimbriados, filamento anterífero filiforme, anteras lineares, ca. $1 \mathrm{~mm}$ compr. Ovário oblongo, ca. $1 \mathrm{~mm}$ compr., estigma capitado, não pulverulento.

Pfaffia cipoana é morfologicamente afim a $P$. denudata da qual se diferencia por apresentar ramos folhosos, folhas lanceoladas a linear-lanceoladas, com 1,5-3 $\times 0,1-0,2 \mathrm{~cm}$, bráctea mediana com bordo hialino, nervura dorsal larga e escura e sépalas oblongas. Já, em $P$. denudata as folhas são lineares a linearlanceoladas, com 1,5-1,8 $\times 0,3-0,6 \mathrm{~cm}$, quando presentes, a bráctea mediana não apresenta bordo hialino e as sépalas são lanceoladas a ovado-lanceoladas.

Esta espécie nova é endêmica, até o presente, ao estado de Minas Gerais, em campos rupestres, com altitudes entre 1.300 $1.500 \mathrm{~m}$. Floresce no mês de maio. O epíteto cipoana refere-se ao local de coleta, na Serra do Cipó, Minas Gerais.

2. Pfaffia rupestris Marchioretto, Miotto \& Siqueira $s p$. nov. Tipo: BRASIL. MINAS GERAIS: Rio Pardo de Minas, estrada Serranópolis-Rio Pardo, Serra de Poções, entre rochas, 13.V.1998, J.R. Pirani, A.C. Marcato, R.C. Forzza, M.C. Assis \& P.E. Labiak 4300 (holótipo PACA; isótipos HRCB, SPF).

Fig. 2

Pfaffia rupestris $a b$ omnibus Pfaffia speciebus differt cauli et ramis valde foliosis, ramis foliis minutis, 0,5-1 cm longis, $1-2 \mathrm{~mm}$ largis, oppositis verticilatis.

Subarbusto, caule ereto, inicialmente escuro e glabro, tornando-se densamente lanoso ou tomentoso, verde-acinzentado até canescente em direção ao ápice, entrenós de $0,5-2 \mathrm{~cm}$ compr. Folhas opostas ou verticiladas, estreito-oblongas, $0,5-1 \times 0,1-$ $0,2 \mathrm{~cm}$, sésseis, ápice agudo, base truncada, faces adaxial e abaxial densamente lanosotomentosas, cinza-esverdeadas. Inflorescência capituliforme, terminal, pedúnculo curto, $2-$ $2,5 \mathrm{~cm}$ compr., lanoso-tomentoso, ráquis tomentosa, três brácteas, a mediana oblonga, hialina, ápice acuminado, uninervada, tricomas no ápice do dorso, ca. 3,5 mm compr., as laterais oblongas, hialinas, ápice acuminado, uninervadas, tricomas no dorso, principalmente no ápice, ca. $3 \mathrm{~mm}$ compr.; entre as brácteas e sépalas tricomas alvacentos, articulados, um pouco maiores que a metade do comprimento das sépalas. Sépalas desiguais, oblongas a oblongo-lanceoladas, trinervadas, ápice agudo, 


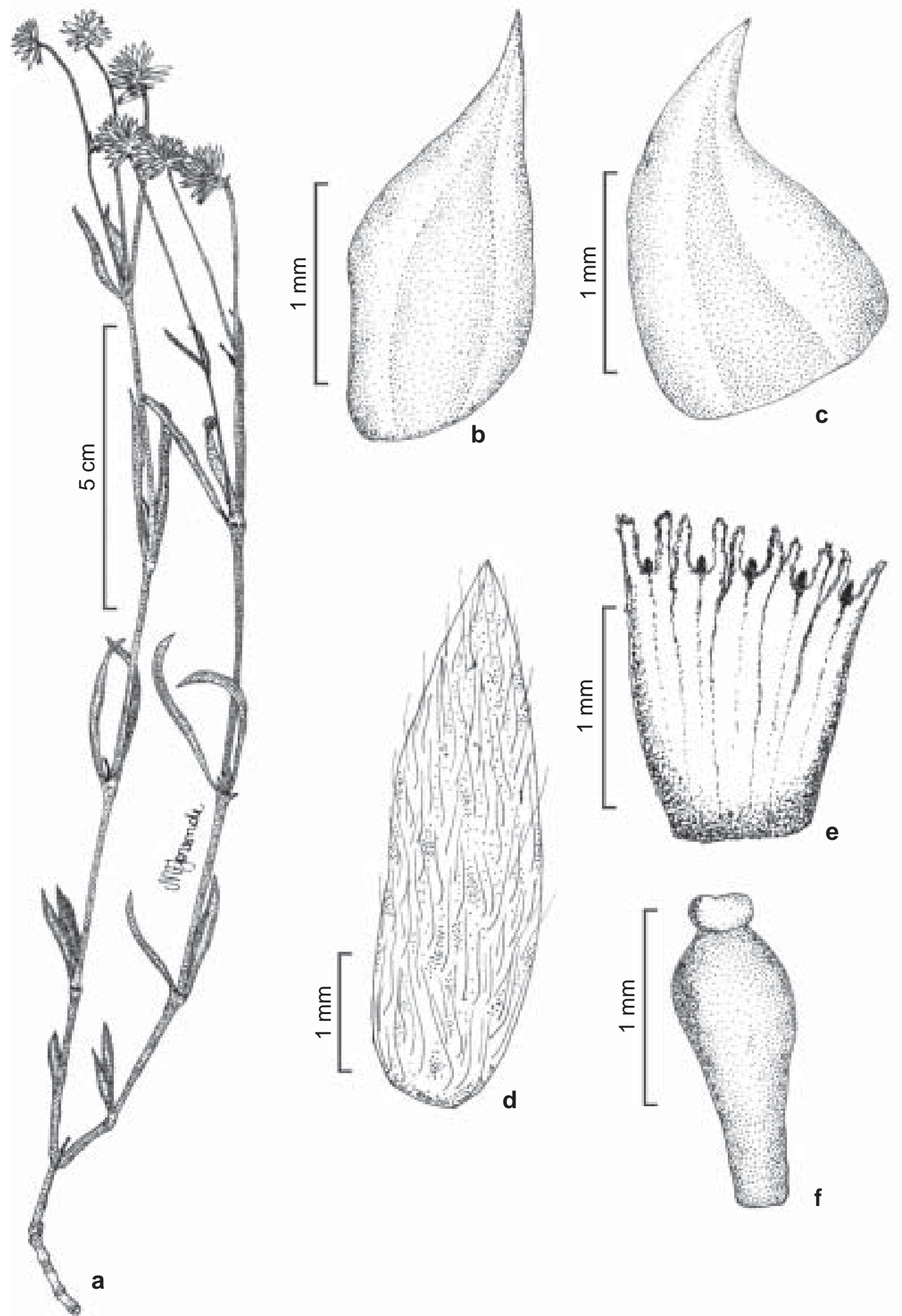

Figura 1 - Pfaffia cipoana Marchioretto, Miotto \& Siqueira - a. hábito; b. bráctea mediana; c. bráctea lateral; d. sépala; e. tubo estaminal; f. ovário. (Hensold 820) 


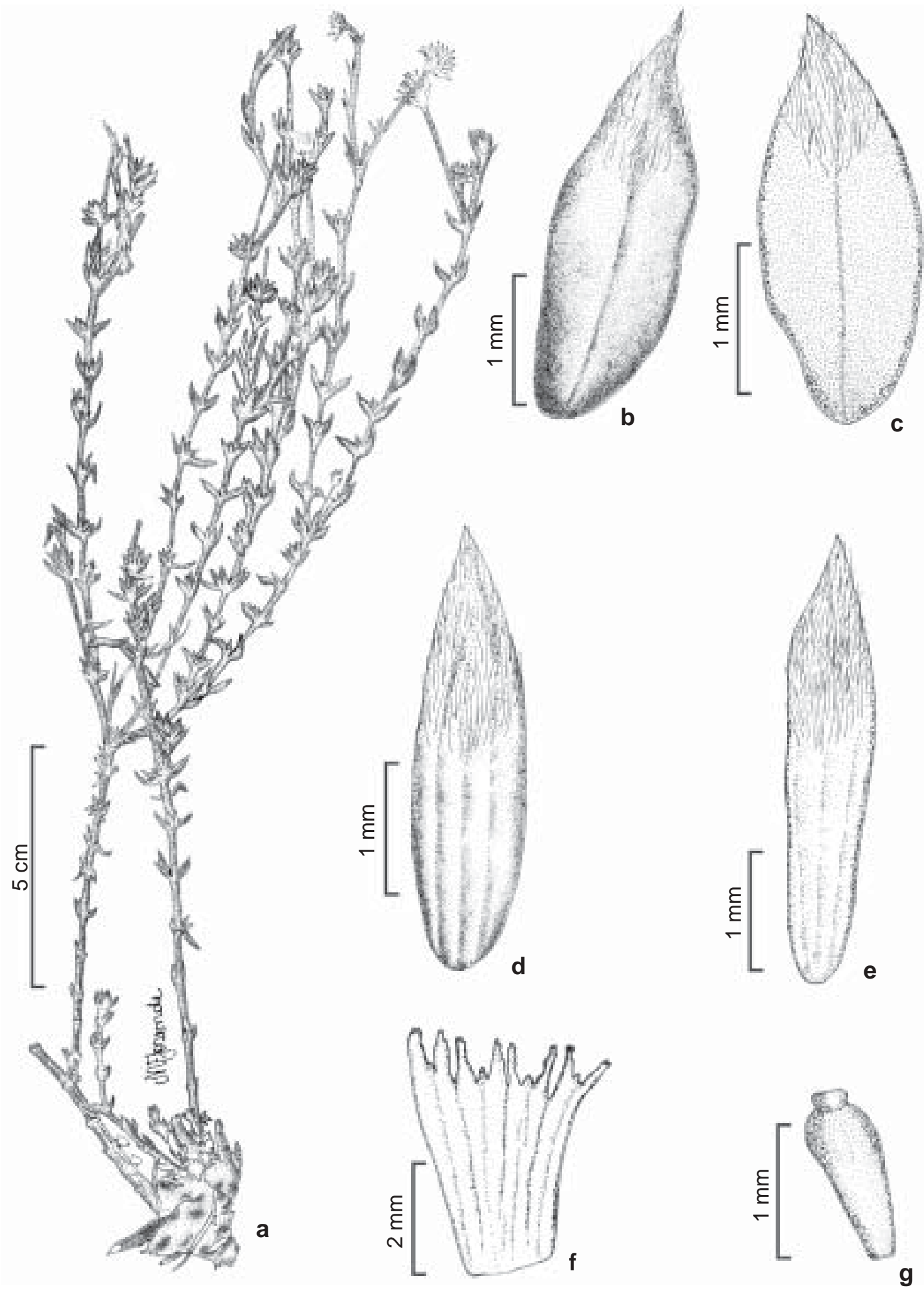

Figura 2 - Pfaffia rupestris Marchioretto, Miotto \& Siqueira - a. hábito; b. bráctea mediana; c. bráctea lateral; d-e. sépalas; f. tubo estaminal; g. ovário. (Pirani 4300) 
pilosas do meio para o ápice na face dorsal, quase hialinas, 3,5-4 $\mathrm{mm}$ compr. Tubo estaminal quase do tamanho das sépalas, filamentos laterais subulado-lanceolados, filamento anterífero agudo, anteras oblongas, ca. $1 \mathrm{~mm}$ compr. Ovário oblongo, ca. $1 \mathrm{~mm}$ compr., estigma capitado, pulverulento.

Pfaffia rupestris diferencia-se das demais espécies de Pfaffia por ser extremamente foliosa, apresentar ramos com folhas muito pequenas com $0,5-1 \mathrm{~cm}$ de comprimento por 1-2 $\mathrm{mm}$ de largura, opostas e verticiladas.

Espécie restrita e endêmica, encontrada até o presente no estado de Minas Gerais em campos rupestres, em altitudes que variam de 620-755 m. De acordo com a coleta a espécie floresce no mês de março. O epíteto rupestris, se refere, ao hábitat da espécie, entre rochas.

\section{Agradecimentos}

Nossos sinceros agradecimentos aos Drs. Egidio Francisco Schmitz e Pedro Ignácio Schmitz pelas diagnoses latinas. À desenhista Maria Virgília Farias Josende pelas ilustrações.

\section{REFERÊNCIAS BIBLIOGRÁFICAS}

Borsch, T. 1995. Three new combinations in Pfaffia (Amaranthaceae) from the New World Tropics. Novon 5: 230-233.

Siqueira, J. C. 1992. O gênero Gomphrena L. (Amaranthaceae) no Brasil. PesquisasBotânica 43: 5-197. 1994/1995. Fitogeografia das Amaranthaceae Brasileiras. PesquisasBotânica 45: 5-21.

.2002. Amaranthaceae In: Wanderley, M. G. L.; Shepherd, G. \& Giulietti, A. M. Flora Fanerogâmica do Estado de São Paulo. V.2. FAPESP-HUCITEC. Pp. 11-30.

\& Grandi, T. S. M. 1986. O gênero Pfaffia Mart. (Amaranthaceae) nos cerrados e campos rupestres de Minas Gerais. Acta Biologica Leopoldensia 8(2): 213-230.

Stützer, O. 1935. Die Gattung Pfaffia mit einem Anhag neur Arten von Alternanthera. Feddes Repertorium Specierum Novarum Regni Vegetabilis 88: 1-49.

Vasconcellos, J. M. O. 1986. Amaranthaceae do Rio Grande do Sul, Brasil. -V. Gêneros Pfaffia Mart. e Gomphrena Mart. Roessléria 8(2):75-127. 